\title{
TRIBUTE TO STEVE FIENBERG
}

\author{
JOHN M. ABOWD
}

U.S. Census Bureau and Cornell University

e-mail address: john.abowd@cornell.edu

As readers of this Journal know, I paid my tribute to Steve Fienberg in my 2016 Julius Shiskin Lecture:

"Finally, I would like to acknowledge the role of Stephen Fienberg of Carnegie Mellon University. I'm sure almost everyone in this auditorium can cite a path-breaking contribution of Steve's that had a major impact on statistics and the federal statistical system. I want to highlight the foresight that he had in gathering researchers from the SDL community and the emerging computer science data-privacy community in Bertinoro, Italy, in 2005. This is where I first met Cynthia Dwork and the team of young cryptographers who were shattering the received wisdom in SDL with methods that Steve recognized as revolutionary. I'm also going to spend much of this lecture on those methods. The last time Steve and I talked about this, at this year's JSM, he confided to me that our big mistake was that 'we did not grow the community fast enough.' I hope this lecture helps solve that problem too." (JPC, 2017, Vol. 7, No. 3 DOl: 10.29012/jpc.v7i3.404)

To which I would now add, that I hope this volume in his honor also expands the community of scholars working on these important issues. As compelling as the cryptographers are, privacy-preserving data analysis must have equal participation from domain scientists, technologists, and statisticians. Good science and strong privacy protections do compete for the same scarce resource (the information in confidential databases), but efficient, workable solutions require input from all these specialists. 